\title{
Green Synthesis of Silver Nanoparticles and Their Bactericidal and Antimycotic Activities against Oral Microbes
}

\author{
Osvelia E. Rodríguez-Luis, ${ }^{1}$ Rene Hernandez-Delgadillo, ${ }^{1}$ \\ Rosa Isela Sánchez-Nájera, ${ }^{1}$ Gabriel Alejandro Martínez-Castañón, ${ }^{2}$ \\ Nereyda Niño-Martínez, ${ }^{3}$ María del Carmen Sánchez Navarro, ${ }^{2}$ \\ Facundo Ruiz, ${ }^{3}$ and Claudio Cabral-Romero ${ }^{1}$ \\ ${ }^{1}$ Facultad de Odontologia, Universidad Autonoma de Nuevo Leon (UANL), 64460 Monterrey, NL, Mexico \\ ${ }^{2}$ Facultad de Estomatologia, UASLP, 78290 San Luis Potosí, SLP, Mexico \\ ${ }^{3}$ Facultad de Ciencias, UASLP, 78290 San Luis Potosí, SLP, Mexico \\ Correspondence should be addressed to Nereyda Niño-Martínez; nereyda_n@yahoo.com and \\ Claudio Cabral-Romero; claudiohubble@hotmail.com
}

Received 11 November 2015; Revised 27 March 2016; Accepted 29 March 2016

Academic Editor: Paulo Cesar Morais

Copyright (C) 2016 Osvelia E. Rodríguez-Luis et al. This is an open access article distributed under the Creative Commons Attribution License, which permits unrestricted use, distribution, and reproduction in any medium, provided the original work is properly cited.

\begin{abstract}
Nanotechnology is a new discipline with huge applications including medicine and pharmacology industries. Although several methods and reducing agents have been employed to synthesize silver nanoparticles, reactive chemicals promote toxicity and nondesired effects on the human and biological systems. The objective of this work was to synthesize silver nanoparticles from Glycyrrhiza glabra and Amphipterygium adstringens extracts and determine their bactericidal and antimycotic activities against Enterococcus faecalis and Candida albicans growth, respectively. 1 and $10 \mathrm{mM}$ silver nitrate were mixed with an extract of Glycyrrhiza glabra and Amphipterygium adstringens. Green silver nanoparticles (AgNPs) were characterized by TEM, VisNIR, FTIR, fluorescence, DLS, TGA, and X-ray diffraction (XRD) analysis. Bactericidal and antimycotic activities of AgNPs were determined by Kirby and Bauer method and cell viability MTT assays. AgNPs showed a spherical shape and average size of $9 \mathrm{~nm}$ if prepared with Glycyrrhiza glabra extract and $3 \mathrm{~nm}$ if prepared with Amphipterygium adstringens extract. AgNPs inhibited the bacterial and fungal growth as was expected, without a significant cytotoxic effect on human epithelial cells. Altogether, these results strongly suggest that AgNPs could be an interesting option to control oral biofilms.
\end{abstract}

\section{Introduction}

Nanotechnology is a relative new discipline with huge applications in many areas including medicine and pharmacology industries $[1,2]$. The increasing development of multidrugresistant strains among pathogen microbes has become one of the most important problems in medicine worldwide [3]. Great advances in nanotechnology have provided a solid foundation for using nanoparticles (NPs) in the fight against pathogen microorganisms, including multidrugresistant bacteria $[2,4,5]$. Previously the biocidal properties of nanoclusters of several metals have been described, mainly, silver, gold, zinc, titanium, and bismuth [6-10]. Aside from their potential metal nanoparticles present cytotoxicity on human cells, this may occur in all reactive chemicals employed in their synthesis and limiting their use in clinical practice [11-14].

The traditional synthesis of silver nanoparticles (AgNPs) uses chemical reducing agents to modify Ag ions to AgNPs [15]. The most common used chemical reducing agents are ascorbic acid [16], hydrazine [17], and sodium borohydride [18]. The use of these composites involves undesired side effects and the biocompatibility of resulting AgNPs is low for being employed in biological systems. Recently new methods based on green synthesis that use environmental compounds as reducing agents are emerging [19-22]. Plants, bacteria, 
fungus, and algae have been used for green synthesis of metal nanoparticles with very good results and water acts as a solvent in the process of green synthesis [23].

AgNPs are synthesized using a green synthesis method. AgNPs are being investigated for application in biomedicine and to be used as bactericide agent or for cancer treatment [24]. Several plants have been used to prepare silver nanoparticles; for example, Alfalfa and Geranium (one of the first plants used for these porpoise) produce nanoparticles with sizes of 2-20 nm and $14-46 \mathrm{~nm}$, respectively [25, 26]. Recently, Phanjom et al. (2012) used Elaeagnus latifolia leaf extract to synthesize AgNPs with diameters of 30-50 nm [27]; also AgNPs with potential cytotoxic effects against breast cancer cells were prepared using Ganoderma neojaponicum Imazeki [28].

The objective of this work was to synthesize silver nanoparticles from Glycyrrhiza glabra and Amphipterygium adstringens and determine their bactericidal and antimycotic activities against Enterococcus faecalis and Candida albicans growth, respectively; to our knowledge this is the first report for the green synthesis of silver nanoparticles using these plants. The obtained results show AgNPs of spherical shape and average size lower than $10 \mathrm{~nm}$. As was expected, AgNPs inhibited the bacterial and fungal growth corroborating their biological properties. Altogether, these results strongly suggest that gAgNPs could be an interesting option to control oral biofilms.

\section{Material and Methods}

2.1. Achievement of Glycyrrhiza glabra and Amphipterygium adstringens Ethanolic Extracts. Bark of Amphipterygium adstringens (Cuachalalate) and root of Glycyrrhiza glabra were employed to get ethanolic extracts following the method previously described by Viveros-Valdez et al., 2008. $250 \mathrm{~g}$ of $A$. adstringens was macerated and put into water in a relation of $50: 50, \mathrm{H}_{2} \mathrm{O}: \mathrm{C}_{2} \mathrm{H}_{6} \mathrm{O}$. In the case of G. glabra extract, methanol was employed to dilute the macerated. Both extracts were maintained in continuous agitation for $24 \mathrm{~h}$ at room temperature, thus getting 3 extractions, and solvent was eliminated by reduced pressure [29]. A phytochemical analysis of extracts was done to partially identify active ingredients through chemical assays like Shinoda, Liebermann Burchard, coumarins, and so forth [30]. The semicharacterized extracts were stocked at $4^{\circ} \mathrm{C}$ until being used to synthesize silver nanoparticles.

2.2. Biosynthesis of Silver Nanoparticles, gAgNPs. All reagents were purchased from Sigma-Aldrich Co. and were used without further purification. Deionized water was used to prepare all the aqueous solutions.

2.3. Preparation of the Extract Solution. For the preparation of the extract solutions, a given amount of the dried extract was diluted with dimethyl sulfoxide DMSO to obtain a final concentration of $0.4 \%(\mathrm{w} / \mathrm{v})$. Once obtained, this solution was stored at $4^{\circ} \mathrm{C}$ and protected from the sunlight until being used.
2.4. Synthesis of Silver Nanoparticles. Under ambient conditions and magnetic stirring, $100 \mu \mathrm{L}$ of the extract solution was added to $25 \mathrm{~mL}$ of either $1 \mathrm{mM}$ or $10 \mathrm{mM} \mathrm{AgNO}_{3}$ aqueous solution (we obtained 4 different samples, two for the Glycyrrhiza glabra extract and two for the Amphipterygium adstringens extract; see labels for each sample in Table 2). Immediately after that, the $\mathrm{pH}$ value of the reaction mixture was adjusted to 11 using a $3.0 \mathrm{M} \mathrm{NaOH}$ solution and then it was stirred for another 15 minutes.

After that time, the $\mathrm{pH}$ value of the reaction mixture was again modified to 1.0 using $\mathrm{HNO}_{3}$ (63\%); this modification of $\mathrm{pH}$ produces a reversible flocculation of the nanoparticles, allowing us to easily separate them from the subproducts of the reaction by centrifugation at $6000 \mathrm{rpm}$. The supernatant was discarded and the pellet was redispersed using deionized water and, if necessary, the $\mathrm{pH}$ was adjusted to 7.0.

To obtain dried powders of the nanoparticles, after the centrifugation, the separated pellet was dried overnight in a conventional oven at $60^{\circ} \mathrm{C}$.

2.5. Characterization of the Silver Nanoparticles. The morphology and size of the silver nanoparticles were analyzed using transmission electron microscopy (TEM) with a JEOL JEM1230 microscope operating at an acceleration voltage of $100 \mathrm{kV}$. TEM images of the prepared nanoparticles were used for the size distribution measurements; the size of 300 particles was measured to obtain the average size. VisNIR absorption spectra were obtained using a CHEMUSB4VIS-NIR (Ocean Optics) spectrophotometer. Hydrodynamic diameter and zeta potential were measured using dynamic light scattering (DLS) with a Zetasizer Nano ZS (Malvern Instruments) operating with a $\mathrm{He}-\mathrm{Ne}$ laser at a wavelength of $633 \mathrm{~nm}$ and a detection angle of $90^{\circ}$ at $25^{\circ} \mathrm{C}$. Fluorescence emission (FLUO) was observed using a USB4000 spectrophotometer (Ocean Optics); samples were excited with a solid state continuous laser $(532 \mathrm{~nm}, 100 \mathrm{~mW})$. All of the above characterization techniques were performed using the aqueous dispersion of the nanoparticles.

Using the dried powders, X-ray diffraction (XRD) patterns were obtained on a GBC-Difftech MMA model, with a $\mathrm{Cu} \mathrm{K} \alpha$ irradiation at $\lambda=1.54 \AA$; thermogravimetric analysis (TGA) was performed in a DSC500 calorimeter (Waters), using a constant heating rate of $2^{\circ} \mathrm{C} / \mathrm{min}$ from room temperature to $1000^{\circ} \mathrm{C}$; infrared spectra (IR) were obtained with a FTIR spectrophotometer (IRAffinity, Shimadzu) from 400 to $4000 \mathrm{~cm}^{-1}$.

2.6. Antimicrobial Activity of AgNPs by Kirby and Bauer Method and Cell Viability MTT Assay. The bactericidal and antifungal activities of AgNPs on Enterococcus faecalis and Candida albicans growth (ATCC numbers: 11420 and 90029) were determined using Kirby and Bauer disk diffusion method [31] and MTT (3-(4,5-dimethylthiazol-2-yl)2,5-diphenyltetrazolium bromide) assay (Biotium, Hayward, CA) [32] following the instructions of the manufacturer. $E$. faecalis and $C$. albicans were grown in trypticase soy broth (TSB, BD DIFCO, Sparks, MD, USA) at $37^{\circ} \mathrm{C}$, overnight in aerobic conditions. $100 \mu \mathrm{L}$ of microbial culture was spread 
on TSB agar plate using a sterile cotton swab. AgNPs were embedded into the agar plate to interfere with bacterial growth. The Petri plate was incubated at $37^{\circ} \mathrm{C}$ overnight and the inhibition of bacterial growth was directly proportional to diameter of halo measured with a Vernier. Experiments were repeated three times to assess the veracity of results.

The cell viability was evaluated by the amount of viable cells stained by 3-(4,5-dimethylthiazol-2-yl)-2,5-diphenyltetrazolium bromide (Biotium, Hayward, CA) which was released with dimethylsulfoxide (DMSO, Sigma-Aldrich Inc., St. Louis, MO, USA). E. faecalis and C. albicans were grown in trypticase soy broth (TSB, BD DIFCO, Sparks, MD, USA) at $37^{\circ} \mathrm{C}$, overnight in aerobic conditions. The microbial cells were counted using a Neubauer chamber and $1 \times 10^{4}$ cells were inoculated in $100 \mu \mathrm{L}$ of trypticase soy broth medium in a 96-well polystyrene plate. Three wells with only trypticase soy broth medium were used as controls for microbial growth and AgNPs at final concentration of 0.1 and $1 \mathrm{mM}$ were added. $1.2 \mathrm{mM}$ of chlorhexidine (Ultradent Products, South Jordan, UT) and $0.2 \mathrm{mM}$ of colloidal silver (Microdyn, Tavistock, B) were employed as positive inhibitors of bacterial growth, while $0.002 \mathrm{mM}$ of amphotericin B (Pisa, Mexico) and $0.2 \mathrm{mM}$ of colloidal silver were used as positive inhibitors of fungal growth. AgNPs at final concentration of 1 and $10 \mathrm{mM}$ were used to assess their antimicrobial activity. The 96-well plate was incubated at $37^{\circ} \mathrm{C}$ overnight. Next, $10 \mu \mathrm{L}$ of MTT was added to each well to get a final concentration of $0.1 \mathrm{mg} / \mathrm{mL}$; the plate was protected against light and incubated at $37^{\circ} \mathrm{C}$ for $2 \mathrm{~h}$. Next, $200 \mu \mathrm{L}$ of dimethyl sulfoxide was added to dissolve the reduced MTT species. The amount of cells alive was determined using a microplate absorbance reader (Biorad, Philadelphia, PA) at $570 \mathrm{~nm}$. The experiments were repeated three times and the measured optical density was analyzed by descriptive statistics.

2.7. Cytotoxicity of Silver Nanoparticles Biosynthesized with G. glabra and A. adstringens Ethanolic Extracts. In order to get insight into possible nondesired effects of AgNPs, in this research we used human epithelial cells (HeLa) to analyze the cytotoxic effects of AgNPs. A confluent monolayer of $1 \times 10^{5}$ HeLa cells (ATTCC Nro. CCL-2) was grown in Minimal Essential Medium (MEM, Invitrogen, Carlsbad, CA) supplemented with $10 \%$ of Fetal Bovine Serum (FBS, Invitrogen, Carlsbad, CA) at $37^{\circ} \mathrm{C}$ with $5 \%$ of $\mathrm{CO}_{2}$ in 96-well microtiter plates (Thermo Fisher Scientific Inc.). It was exposed to $1-0.015 \mathrm{mM}$ of AgNPs for $24 \mathrm{~h}$, and the possible cytotoxic effect was detected by MTT (3-(4,5-dimethylthiazol-2-yl)2,5-diphenyltetrazolium bromide) assay (Biotium, Hayward, CA) [32]. As negative control, cells without nanoparticles were employed. $10 \mu \mathrm{L}$ of MTT was added to each well; the plate was protected against light and incubated at $37^{\circ} \mathrm{C}$ for $2 \mathrm{~h}$. Next, the medium was removed carefully and then $100 \mu \mathrm{L}$ of dimethyl sulfoxide was added to dissolve the reduced MTT species. The amount of cells alive was determined using a microplate absorbance reader (Biorad, Philadelphia, PA) at $570 \mathrm{~nm}$. The experiments were repeated three times and the measured optical density was analyzed by descriptive statistics.
TABLE 1: Phytochemical analysis of ethanolic extracts of Glycyrrhiza glabra root and Amphipterygium adstringens bark.

\begin{tabular}{lcc}
\hline Phytochemical component & $\begin{array}{c}\text { Glycyrrhiza } \\
\text { glabra }\end{array}$ & $\begin{array}{c}\text { Amphipterygium } \\
\text { adstringens }\end{array}$ \\
\hline Alkaloids & $\mathrm{ND}$ & $\mathrm{ND}$ \\
Flavonoids & + & $\mathrm{ND}$ \\
Carbohydrates & + & + \\
Saponins & $\mathrm{ND}$ & $\mathrm{ND}$ \\
Tannins & + & + \\
Double bonds & + & + \\
Carbonyl groups & + & + \\
Sterols and triterpenes & + & + \\
Coumarins & + & + \\
Sesquiterpene lactones & $\mathrm{ND}$ & $\mathrm{ND}$ \\
Quinones & $\mathrm{ND}$ & $\mathrm{ND}$ \\
\hline
\end{tabular}

+: identified; ND: not detected.

\section{Results}

3.1. Glycyrrhiza glabra and Amphipterygium adstringens Ethanolic Extracts. The phytochemical screening of extracts showed the presence of tannins, sterols, triterpenes, and coumarins (Table 1). Flavonoids were detected in G. glabra extract but they were undetectable in $A$. adstringens extract. This result is very interesting due to early reports indicating a clear correlation between strong antioxidant activity and phenolic and flavonoids contents [33]. In theory, the major content in flavonoids in G. glabra extract could reduce silver nitrate more successfully than $A$. adstringens extracts.

3.2. Synthesis of Nanoparticles. The addition of the extract to the $\mathrm{AgNO}_{3}$ solution produces a change in color from colorless to pale yellow; when we added the $\mathrm{NaOH}$ solution the reaction mixture immediately changes from pale yellow to light brown (for the $1 \mathrm{mM}$ solutions) and to black (for the $10 \mathrm{mM}$ solutions); this change in color is an indicator of the immediate formation of the nanoparticles; the addition of $\mathrm{NaOH}$ in a green synthesis has already been reported by Singh et al. (2009); they also used $\mathrm{NaOH}$ as an accelerator of the reaction [34].

During the next 15 minutes of stirring an Ostwald ripening process occurs and allows the population of nanoparticles to be more homogeneous in size. No important changes in the properties of the silver nanoparticles were observed when the concentration of the silver nitrate solution changed.

3.3. Characterization of Silver Nanoparticles. Figure 1 presents TEM images and histograms of the four samples obtained in this work; all of them have a narrow particle size distribution and spherical morphology. As we can see, samples prepared using the Gg extract are bigger than samples prepared using the Aa extract (see Table 2). Table 2 also presents the results of the DLS analysis; it can be observed that the hydrodynamic size of all samples is bigger probably due to the presence of biomolecules in their surface (the presence of these biomolecules was further confirmed by FTIR and 

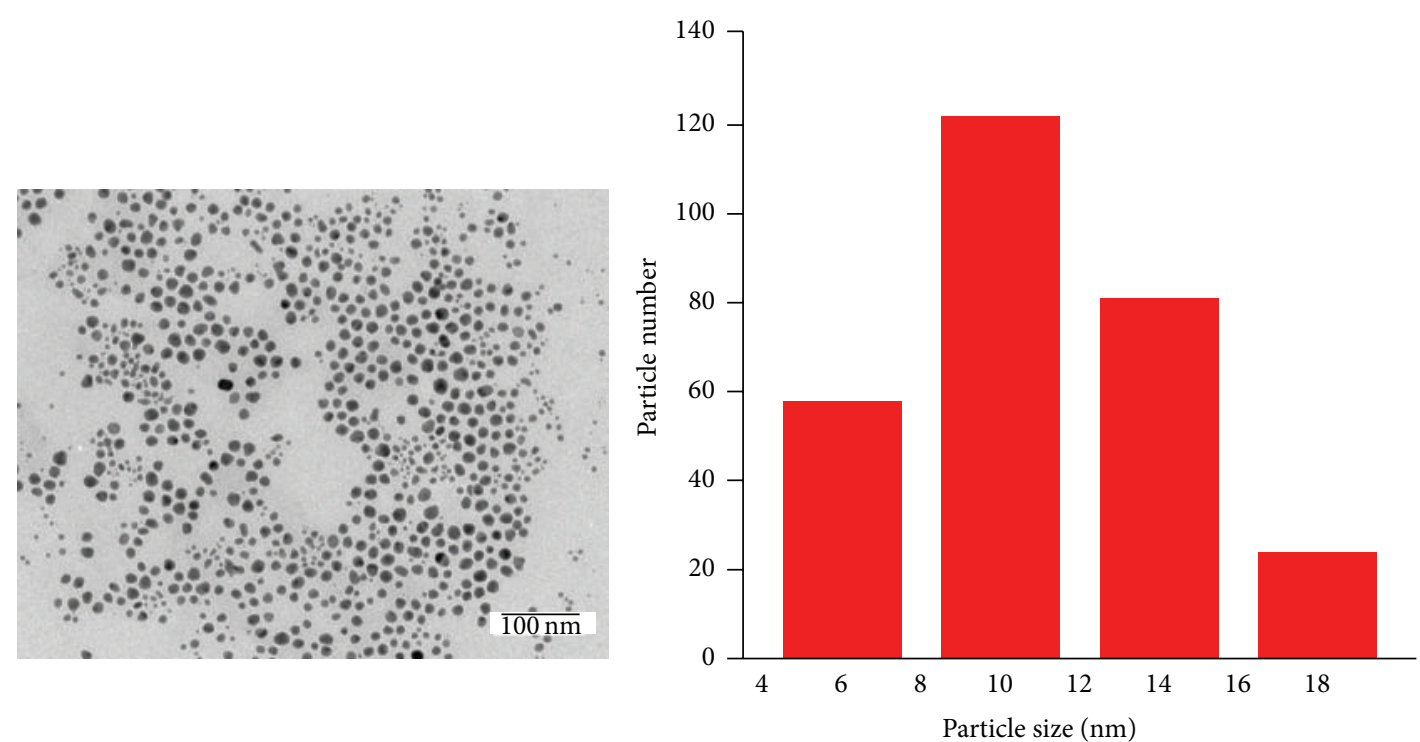

(a)

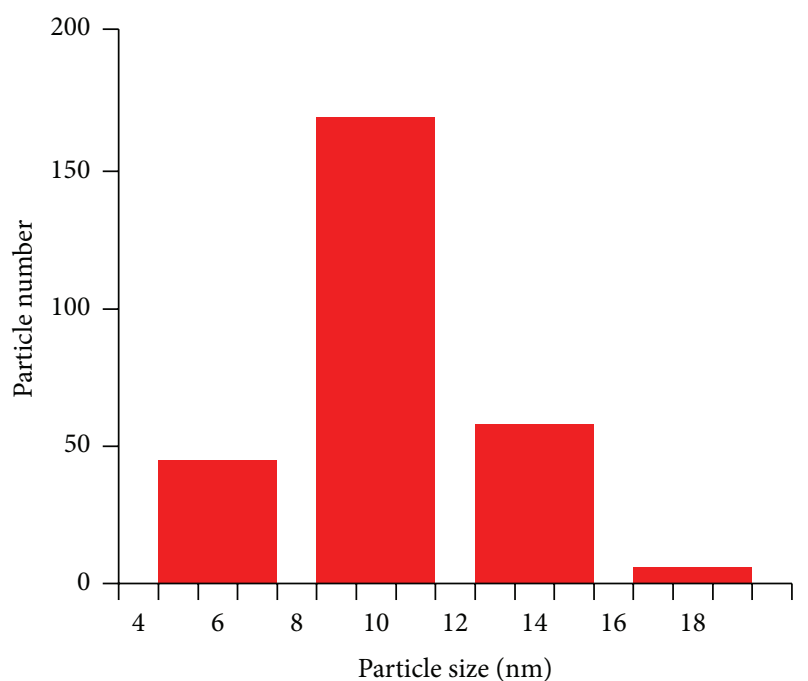

(b)

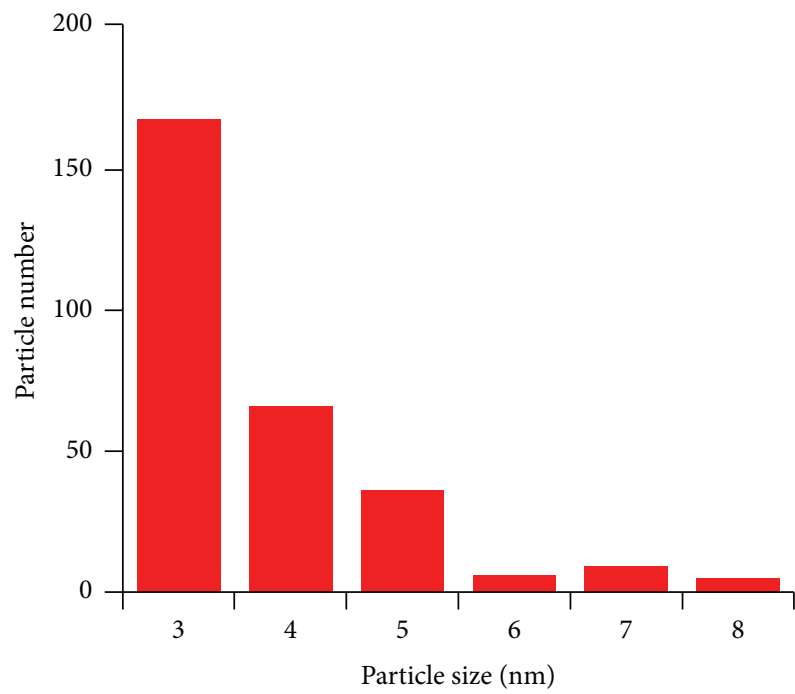

(c)

Figure 1: Continued. 

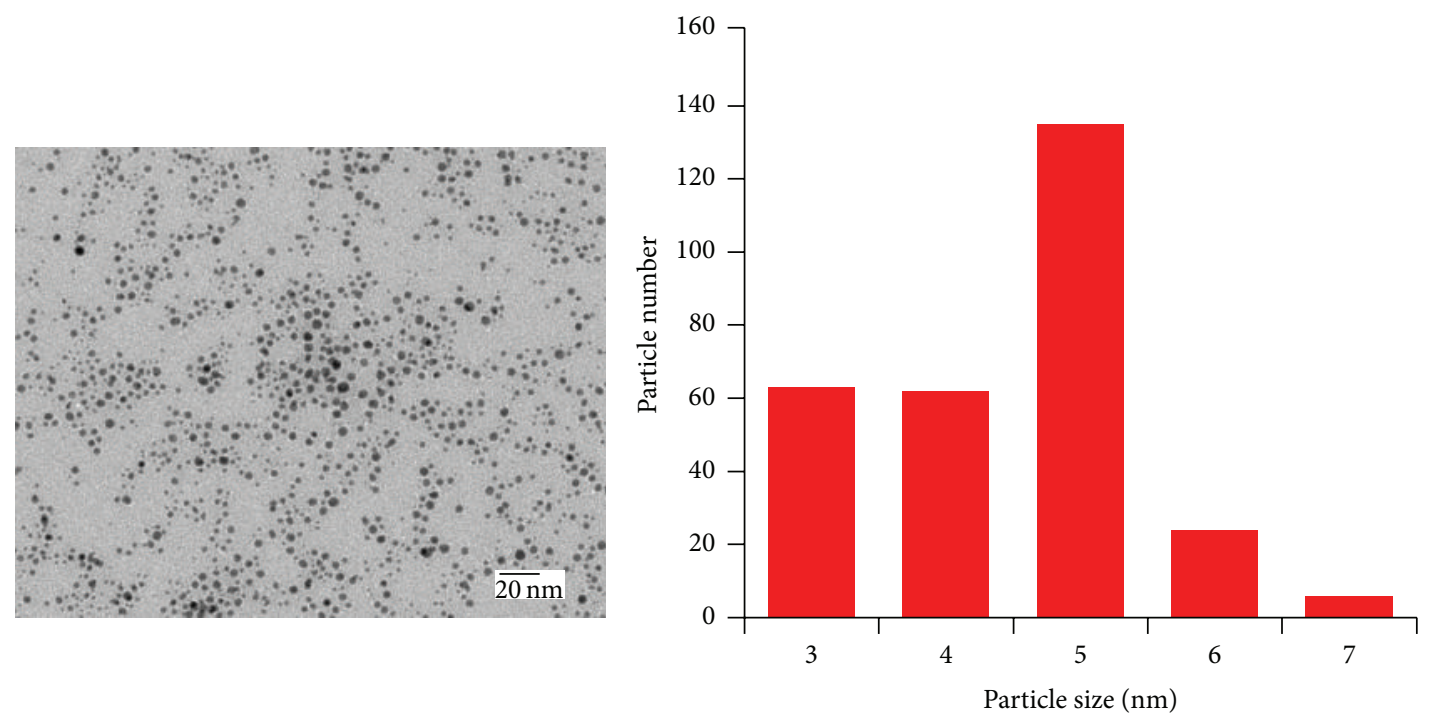

(d)

FIGURE 1: TEM images and histograms for size distribution of silver nanoparticles biosynthesized from Glycyrrhiza glabra and Amphipterygium adstringens. (a) Sample AgG1, (b) sample AgG10, (c) sample AgA1, and (d) sample AgA10.

TABLE 2: Size and zeta potential of the four samples prepared in this work.

\begin{tabular}{lccc}
\hline Sample $^{*}$ & $\begin{array}{c}\text { Size TEM } \\
\mathrm{M} \pm \text { SD }(\mathrm{nm})\end{array}$ & $\begin{array}{c}\text { Hydrodynamic } \\
\text { diameter } \\
\mathrm{M} \pm \text { SD }(\mathrm{nm})\end{array}$ & Zeta potential $(\mathrm{mV})$ \\
\hline AgG1 & $9.7 \pm 3.8$ & $25.39 \pm 3.89$ & $-42.5 \pm 11.2$ \\
AgG10 & $9.5 \pm 2.9$ & $7.892 \pm 0.82$ & $-31.9 \pm 9.12$ \\
AgA1 & $3.1 \pm 1.2$ & $133.7 \pm 24.16$ & $-50.9 \pm 10.3$ \\
AgA10 & $3.9 \pm 1.1$ & $42.69 \pm 7.24$ & $-42.3 \pm 7.52$ \\
\hline
\end{tabular}

${ }^{*} \mathrm{G}$ means samples prepared with Glycyrrhiza glabra and A means samples prepared with Amphipterygium adstringens. 1 and 10 are for samples prepared with $\mathrm{AgNO}_{3}$ at 1 and $10 \mathrm{mM}$, respectively.

TGA analyses); potential zeta values range from $-31.9 \mathrm{mV}$ to $-50.9 \mathrm{mV}$.

The Vis-NIR spectra are presented in Figure 2; differences in size are not reflected in the position of the surface plasmon resonance (SPR); all samples have the characteristic SPR of silver nanoparticles at $420 \mathrm{~nm}$; these spectra are narrow reflecting the narrow particle size distribution of the samples; it has been reported that the nature of the extract modifies the position of the plasmon and similar results were reported for nanoparticles synthesized with Chrysopogon zizanioides, Prosopis juliflora, Moringa oleifera, and Indigofera aspalathoides [35].

Figure 3 shows the diffraction patterns of the samples obtained at $10 \mathrm{mM} \mathrm{AgNO}_{3}$ solution for both extracts; samples can be indexed as pure metallic silver (JCPDS 04-0783) without the presence of any other phases; broader peaks can be seen for sample AgA10 due to the lower particle size and probably due to a lower crystallinity.

FTIR spectra are shown in Figure 4; we found peaks for both samples (AgA and AgG) at $1015 \mathrm{~cm}^{-1}$ (C-N stretch, aliphatic amines), $1385 \mathrm{~cm}^{-1}$ [C-C stretch (in-ring), aromatics], $1595 \mathrm{~cm}^{-1}$ (N-H bend, primary amines), $1737 \mathrm{~cm}^{-1}$
( $\mathrm{C}=\mathrm{O}$ stretch; esters, saturated aliphatic), $1990 \mathrm{~cm}^{-1}(-\mathrm{C} \equiv \mathrm{C}-$ stretch, alkynes), $2849 \mathrm{~cm}^{-1}$ (H-C=O: C-H stretch, aldehydes), $2920 \mathrm{~cm}^{-1}$ (C-H stretch, alkanes), $3302 \mathrm{~cm}^{-1}$ only for $\mathrm{G}$ extract (O-H stretch, H-bonded; alcohols, phenols), and $3758 \mathrm{~cm}^{-1}$ (O-H stretch, primary alcohol) only for $\mathrm{G}$ extract; similar results were reported by $[36,37]$.

As a remarkable feature of the nanoparticles prepared with the extracts of both $A$. adstringens and G. glabra we found that when irradiated with a $532 \mathrm{~nm}$ wavelength laser, they present an emission band with a maximum at $580 \mathrm{~nm}$ (Figure 5). This emission band is most probably coming from the extract molecules in the surface of the silver nanoparticles because it has been reported that only ultrasmall metal nanoclusters could present this property intrinsically [38].

3.4. Antimicrobial Activity of AgNPs by Kirby and Bauer Method and Cell Viability MTT Assay. In order to determine if the biosynthesized silver nanoparticles have bactericidal and antimycotic activities Kirby and Bauer disk diffusion assays were performed. The results showed that inhibition of Enterococcus faecalis and Candida albicans growth with AgNPs developed with both extracts (samples AgA10 and AgG10) as can be seen in Figure 6 with average inhibition zone of $10 \mathrm{~mm}$. Samples AgA1 and AgG1 did not show a relevant inhibition of microbial growth; this may be due to incomplete reduction of silver nitrate or due to the extract molecules surrounding the surface of the nanoparticles causing agglomeration and passivation (see Figure S1 in Supplementary Material available online at http://dx.doi.org/10.1155/2016/9204573). These results were expected based on the size and morphology of AgNPs, since spherical morphology, concentration, and low size are tightly related to their biological action. With the intention of corroborating the antimicrobial activity of AgNPs, cell viability MTT assays were carried out. Again silver nanoparticles 


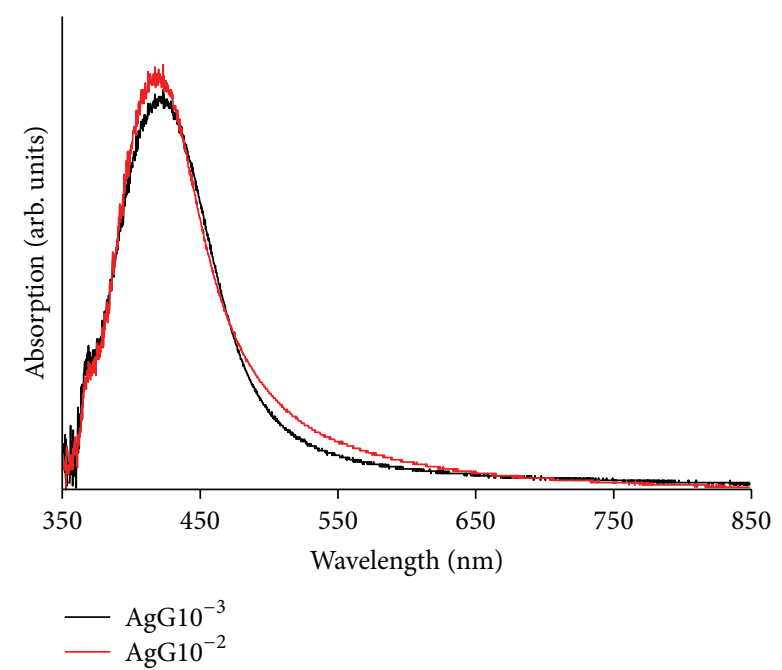

(a)

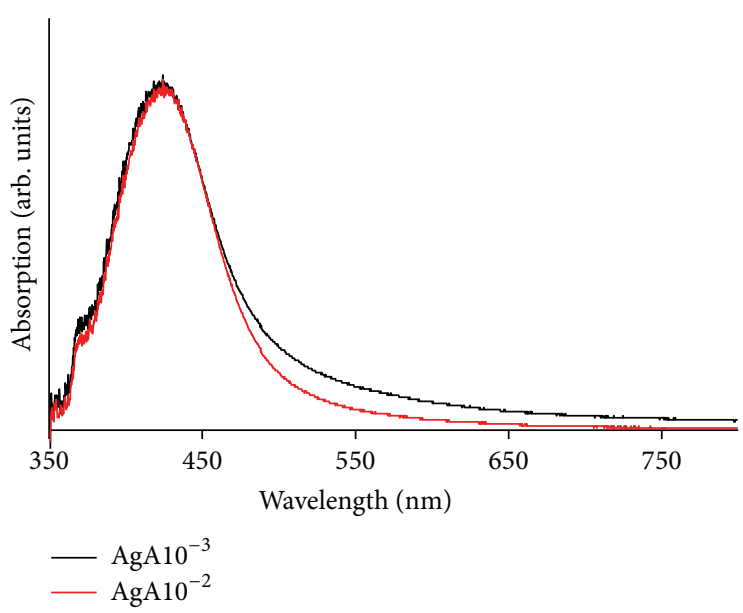

(b)

Figure 2: Vis-NIR spectra of the silver nanoparticles. (a) Samples prepared with Gg extract and (b) samples prepared with Aa extract. The characteristic surface plasmon resonance is located at $420 \mathrm{~nm}$ for each sample.

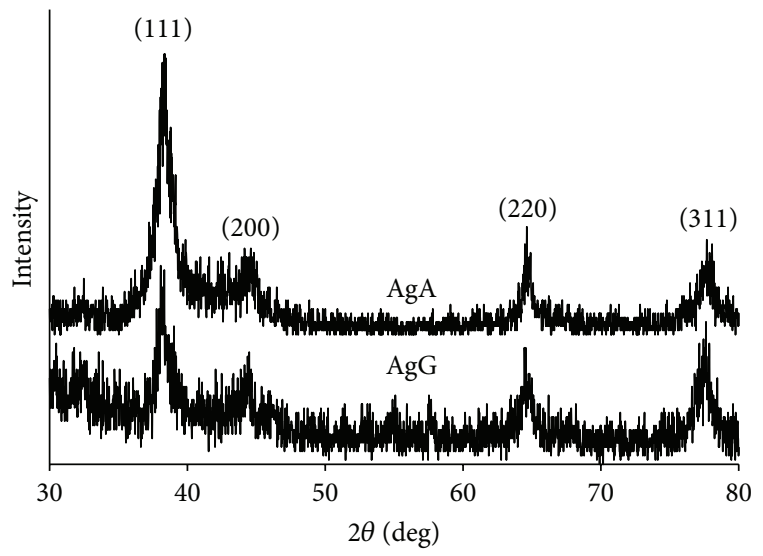

Figure 3: X-ray diffraction patterns of the samples obtained at the higher concentrations of $\mathrm{AgNO}_{3}$. Samples were identified as pure silver.

exhibited bactericidal and fungicidal activities, decreasing the microbial growth until 90\% (Figures 6 and 7). To compare the bactericidal activity of silver nanoparticles $1.2 \mathrm{mM}$ of chlorhexidine and $0.2 \mathrm{mM}$ of colloidal silver were employed, while for antimycotic activity $2.5 \mu \mathrm{g} / \mathrm{mL}$ of B amphotericin and $0.2 \mathrm{mM}$ of colloidal silver were used. $1 \mathrm{mM}$ of silver nanoparticles inhibited $90 \%$ of bacterial growth, while $76 \%$ and $41 \%$ were blocked by chlorhexidine and colloidal silver, respectively. $1 \mathrm{mM}$ of silver nanoparticles inhibited $78 \%$ of fungal growth while amphotericin B and colloidal silver interfere with $81 \%$ and $41 \%$ of fungal growth. In summary, silver nanoparticles synthesized by green method compete in efficacy with commercial products.

3.5. Cytotoxicity of AgNPs on Human Epithelial Cells. The cytotoxic effect of biosynthesized silver nanoparticles was evaluated in human epithelial cells by cell viability MTT

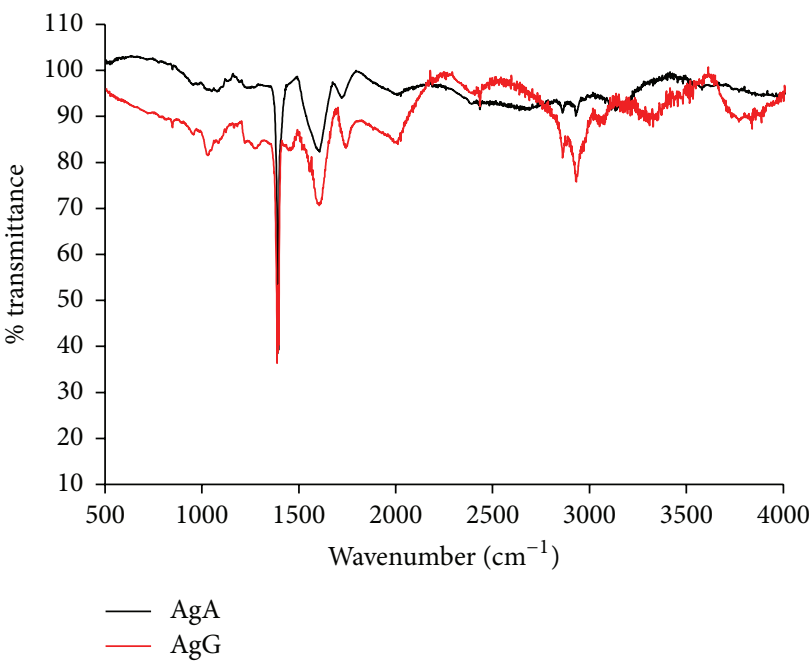

FIGURE 4: FTIR analysis of the functional groups adsorbed on the surface of the silver nanoparticles.

assay. The obtained results indicate that silver nanoparticles developed with $A$. adstringens extract were more toxic to human cells instead of nanoparticles synthetized with $G$. glabra extract (Figure 8). The cytotoxic potential of silver nanoparticles on human cells $[11,15]$ is well described; however, silver nanoparticles synthesized with G. glabra extract showed less side effects and they exhibited a good antimicrobial activity. In summary, side effects and antimicrobial activity must be evaluated before a possible clinical use of this kind of nanoparticles.

\section{Discussion}

Nanotechnology is a relative new discipline with high potential in pharmaceutical industry and biomedical sciences 


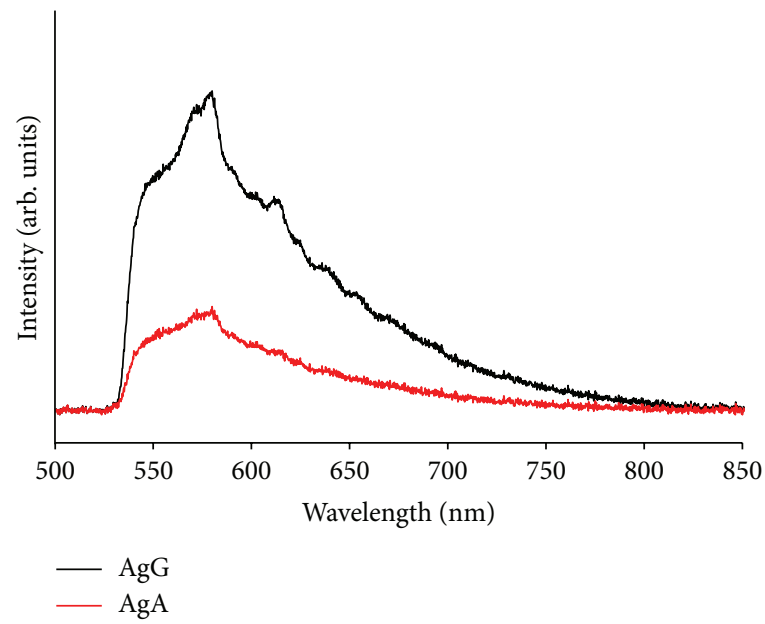

FIGURE 5: Emission spectra of AgNPs prepared in this work. A maximum at $580 \mathrm{~nm}$ can be observed. The excitation was done at $532 \mathrm{~nm}$, $100 \mathrm{~mW}$ power.
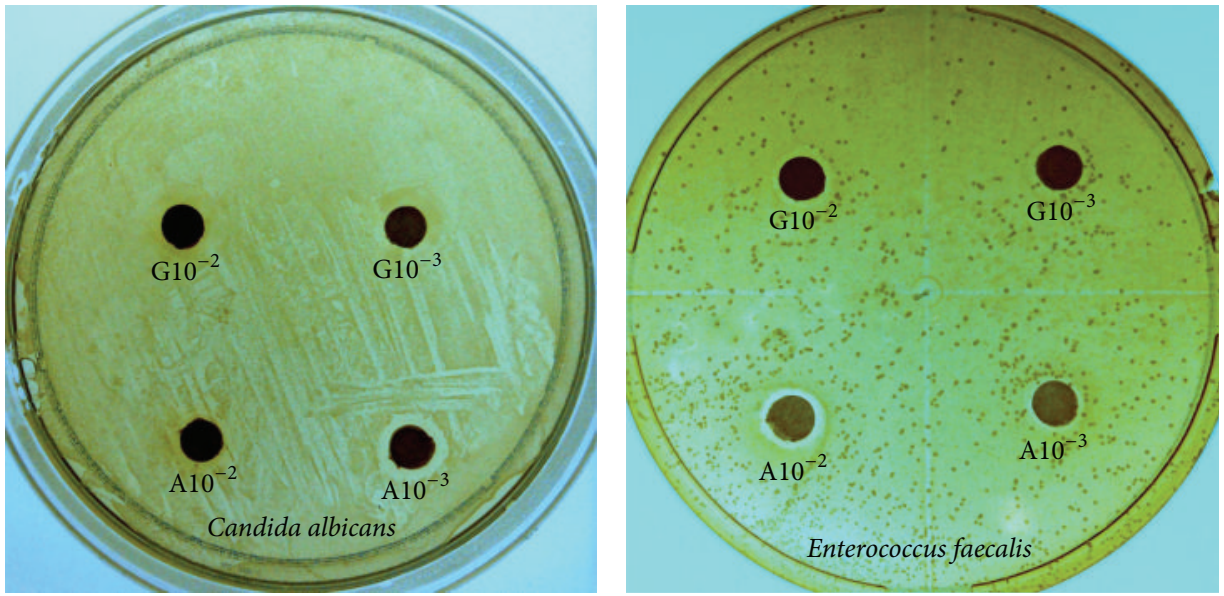

Figure 6: Antimicrobial activity of silver nanoparticles biosynthesized against Enterococcus faecalis and Candida albicans growth. The antimycotic activity of AgNPs was tested against C. albicans and bactericidal activity against E. faecalis employing Kirby and Bauer diffusion disk method. The average diameter halo of microbial inhibition is proportional to the activity of AgNPs. G means Glycyrrhiza glabra and A Amphipterygium adstringens, respectively, diluted $10^{-2}$ or $10^{-3}$.

[39-43]. Nanotechnology applied to medicine tackles fundamental problems like cancer treatment, multiresistance among pathogen microorganisms, vaccines, biotechnology devices, molecular machine systems, and so forth. Nanoparticle-based therapy would be the evolutionated medical treatment with "smart" therapeutics that is simultaneously more potent with less toxic drugs [5]. Metallic nanoparticles are frequently developed by chemical and physical methods [44]. However, in order to look for ecofriendly and green synthesis of metallic NPs diverse biological entities like microorganisms, plant extracts, and enzymes are being employed [44].

In this work we describe a green method to synthesize silver nanoparticles employing Glycyrrhiza glabra and Amphipterygium adstringens ethanolic extracts; to our knowledge this is the first report for the green synthesis of silver nanoparticles using extracts of these plants. The name and structure of the constituents in the ethanolic extracts of Glycyrrhiza glabra and Amphipterygium adstringens have been reported elsewhere; for Glycyrrhiza glabra, Alwan et al. (2015) [45] reported glycyrrhizic acid as the main biologically active component and triterpene saponins, flavonoids, isoflavonoids, and chalcones as secondary components; molecular structures of these compounds can be found in the review of Asl and Hosseinzadeh (2008) [46-48]. For Amphipterygium adstringens, Navarrete et al. (2005) [49] mention triterpenoids and long-chain phenols as the major components of the methanolic extracts; molecular structures can be found in Khadem and Marles (2010) [47, 50, 51].

In our work, in addition to the molecules already reported we found the presence of tannins (see Table 1); tannins are polyphenolic molecules present in most natural extracts.

Although it is possible that all molecules in the extracts play a role in the nucleation of silver nanoparticles we believe that tannins play the major role. In our procedure (for both extracts) the nucleation begins with the addition of 


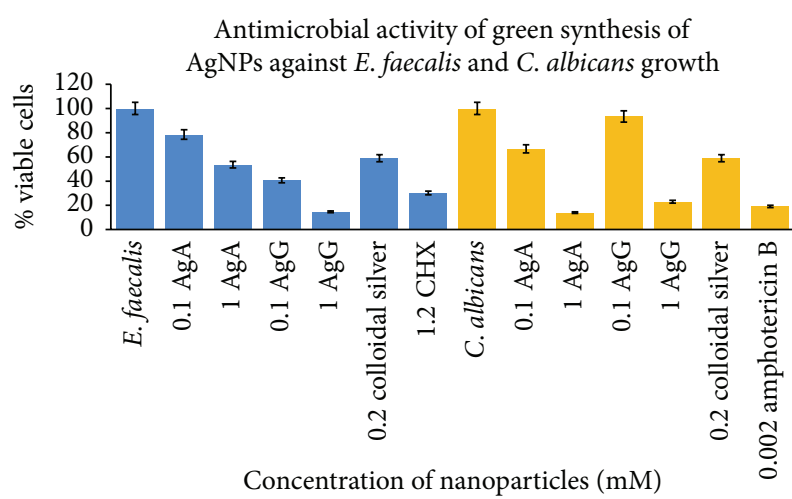

Figure 7: Antimicrobial activity of AgNPs against Enterococcus faecalis and Candida albicans growth. The $y$-axis shows the percent of viable cells. As growing control of bacteria or fungus culture media were added. AgNPs synthesized with Aa or Gb extracts were used at final concentrations of 0.1 and $1 \mathrm{mM} .1 .2 \mathrm{mM}$ of chlorhexidine and $0.2 \mathrm{mM}$ of colloidal silver were employed as positive inhibitors of bacterial growth, while $0.002 \mathrm{mM}$ of amphotericin B and $0.2 \mathrm{mM}$ of colloidal silver were used as positive inhibitors of fungal growth. The bactericidal and antimycotic activities of AgNPs were measured after $18 \mathrm{~h}$ after exposition. All experiments were done by triplicate to assess the veracity of results.

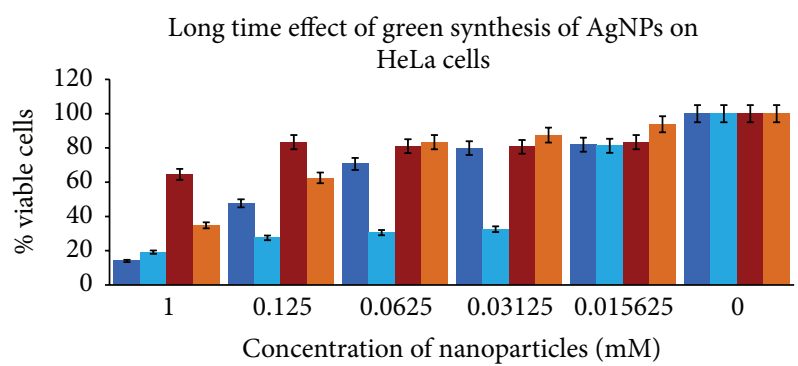

$$
\begin{aligned}
& \text { - Amphipterygium adstringens } 24 \mathrm{~h} \\
& \text { - Amphipterygium adstringens } 48 \mathrm{~h}
\end{aligned}
$$

FIgURE 8: Cytotoxicity of silver nanoparticles determined by cell viability MTT assays. The possible cytotoxic effect of AgNPs synthesized with different concentrations of $\mathrm{Aa}$ or Gg extracts was evaluated in HeLa cells. As positive control HeLa cells growing in culture media were used. All experiments were done in triplicate to assess the veracity of results.

$\mathrm{NaOH}$; this change in the $\mathrm{pH}$ hydrolyzes tannins into glucose and gallic acid; once gallic acid is formed the reduction of silver ions is achieved by the oxidation reaction of phenol groups. Following the results of the infrared analysis we propose that tannins, flavonoids, and carbohydrates take part in the stabilization process of silver nanoparticles. Silver nanoparticles obtained were spherical in shape with an average size under $10 \mathrm{~nm}$; here, flavonoids and tannins are the molecules responsible for the reduction and stabilization of the nanoparticles through their-OH groups. These results are similar to AgNPs obtained through green synthesis employing Artemisia absinthium aqueous extract and bark extracts of Ficus benghalensis and Azadirachta indica as reductor agents $[48,50]$. Their efficacy in inhibiting the Enterococcus faecalis and Candida albicans growth was similar to that obtained with chemical methods [18], competing against commercial products even better than colloidal silver. AgNPs synthesized with G. glabra show more antimicrobial activity than nanoparticles developed with $A$. adstringens. Previous reports indicate a clear correlation between strong antioxidant activity and phenolic and flavonoids contents [33] and the phytochemical analysis showed the presence of flavonoids only in G. glabra ethanolic extracts. These flavonoids and the major quantity of the G. glabra extract in the surface of the nanoparticles (see Figure S2) compared with those prepared with the $A$. adstringens extract could be responsible for the differences in the antibacterial activity.

It would be interesting to try the synthesis of AgNPs with purified flavonoids and compare the biocidal activity of the obtained nanoparticles.

When cytotoxicity of AgNPs was explored on human epithelial cells, the results showed that the addition of AgNPs developed with $A$. adstringens extract was more toxic to human cells instead of nanoparticles synthetized with $G$. glabra extract (Figure 8). Several reports described toxic effect of silver nanoparticles on human cells, limiting their use in clinical treatments [15]. However, green synthesis did not exclude cytotoxicity in silver nanoparticles like Safaepour report in 2009 using Pelargonium graveolens and Azadirachta indica as reductor agents [51]. More studies are needed to understand the complete effects of employing biological systems to biosynthesize metallic nanoparticles.

\section{Conclusions}

In summary, silver nanoparticles biosynthesized with Glycyrrhiza glabra root and Amphipterygium adstringens bark extracts inhibited the bacterial and fungal growth suggesting that green synthesis could be an interesting option to develop silver nanoparticles with biocidal properties.

\section{Competing Interests}

The authors of this paper declare that there are no potential competing interests.

\section{Acknowledgments}

The authors wish to thank CONACyT for financing Projects 169020, 178261, and 183825. Financial support for payment of the processing charges was made by Programa para el Desarrollo Profesional Docente para el Tipo Superior (PRODEP 2014 and 2015). N. Niño-Martínez wants to thank Fondo de Apoyo a la Investigación (FAI, UASLP 2015, Grant C15-FAI04-77.77) and PRODEP 2015 (Grant DSA/103.5/15/6988).

\section{References}

[1] L. E. da Silva, "Nanomachines and "nanosolutions": they are changing the perspective of medical treatments," Recent Patents on Anti-Infective Drug Discovery, vol. 10, no. 2, pp. 74-75, 2015.

[2] R. Y. Pelgrift and A. J. Friedman, "Nanotechnology as a therapeutic tool to combat microbial resistance," Advanced Drug Delivery Reviews, vol. 65, no. 13-14, pp. 1803-1815, 2013. 
[3] H. M. Lode, R. Stahlmann, and M. Kresken, "Multiresistant pathogens-a challenge for clinicians," Zentralblatt fur Chirurgie, vol. 138, no. 5, pp. 549-553, 2013.

[4] C. You, C. Han, X. Wang et al., "The progress of silver nanoparticles in the antibacterial mechanism, clinical application and cytotoxicity," Molecular Biology Reports, vol. 39, no. 9, pp. 91939201, 2012.

[5] N. Desai, "Challenges in development of nanoparticle-based therapeutics," AAPS Journal, vol. 14, no. 2, pp. 282-295, 2012.

[6] J. S. Kim, E. Kuk, K. N. Yu et al., "Antimicrobial effects of silver nanoparticles," Nanomedicine: Nanotechnology, Biology, and Medicine, vol. 3, no. 1, pp. 95-101, 2007.

[7] W.-C. Huang, P.-J. Tsai, and Y.-C. Chen, "Functional gold nanoparticles as photothermal agents for selective-killing of pathogenic bacteria," Nanomedicine, vol. 2, no. 6, pp. 777-787, 2007.

[8] J. C. Castillo-Martínez, G. A. Martinez-Castanon, F. MartínezGutierrez et al., "Antibacterial and antibiofilm activities of the photothermal therapy using gold nanorods against seven different bacterial strains," Journal of Nanomaterials, vol. 2015, Article ID 783671, 7 pages, 2015.

[9] Y.-H. Hsueh, W.-J. Ke, C.-T. Hsieh, K.-S. Lin, D.-Y. Tzou, and C.-L. Chiang, "ZnO nanoparticles affect bacillus subtilis cell growth and biofilm formation," PLoS ONE, vol. 10, no. 6, Article ID e0128457, 2015.

[10] N. Nataraj, G. S. Anjusree, A. A. Madhavan et al., "Synthesis and anti-staphylococcal activity of $\mathrm{TiO}_{2}$ nanoparticles and nanowires in ex vivo porcine skin model," Journal of Biomedical Nanotechnology, vol. 10, no. 5, pp. 864-870, 2014.

[11] S. Gaillet and J.-M. Rouanet, "Silver nanoparticles: their potential toxic effects after oral exposure and underlying mechanisms-a review," Food and Chemical Toxicology, vol. 77, pp. 5863, 2015.

[12] P. M. Favi, M. Gao, L. Johana Sepúlveda Arango et al., "Shape and surface effects on the cytotoxicity of nanoparticles: gold nanospheres versus gold nanostars," Journal of Biomedical Materials Research Part: A, vol. 103, no. 11, pp. 3449-3462, 2015.

[13] M. Czajka, K. Sawicki, K. Sikorska, S. Popek, M. Kruszewski, and L. Kapka-Skrzypczak, "Toxicity of titanium dioxide nanoparticles in central nervous system," Toxicology in Vitro, vol. 29, no. 5, pp. 1042-1052, 2015.

[14] T.-H. Chen, C.-C. Lin, and P.-J. Meng, "Zinc oxide nanoparticles alter hatching and larval locomotor activity in zebrafish (Danio rerio)," Journal of Hazardous Materials, vol. 277, pp. 134-140, 2014.

[15] C. A. dos Santos, M. M. Seckler, A. P. Ingle et al., "Silver nanoparticles: therapeutical uses, toxicity, and safety issues," Journal of Pharmaceutical Sciences, vol. 103, no. 7, pp. 1931-1944, 2014.

[16] S. A. AL-Thabaiti, F. M. Al-Nowaiser, A. Y. Obaid, A. O. AlYoubi, and Z. Khan, "Formation and characterization of surfactant stabilized silver nanoparticles: a kinetic study," Colloids and Surfaces B: Biointerfaces, vol. 67, no. 2, pp. 230-237, 2008.

[17] Z. Khan, S. A. Al-Thabaiti, E. H. El-Mossalamy, and A. Y. Obaid, "Studies on the kinetics of growth of silver nanoparticles in different surfactant solutions," Colloids and Surfaces B: Biointerfaces, vol. 73, no. 2, pp. 284-288, 2009.

[18] L. F. Espinosa-Cristóbal, G. A. Martínez-Castañón, R. E. Martínez-Martínez et al., "Antibacterial effect of silver nanoparticles against Streptococcus mutans," Materials Letters, vol. 63, no. 29, pp. 2603-2606, 2009.
[19] P. Elia, R. Zach, S. Hazan, S. Kolusheva, Z. Porat, and Y. Zeiri, "Green synthesis of gold nanoparticles using plant extracts as reducing agents," International Journal of Nanomedicine, vol. 9, no. 1, pp. 4007-4021, 2014.

[20] L. David, B. Moldovan, A. Vulcu et al., "Green synthesis, characterization and anti-inflammatory activity of silver nanoparticles using European black elderberry fruits extract," Colloids and Surfaces B: Biointerfaces, vol. 122, pp. 767-777, 2014.

[21] K. Veerakumar and M. Govindarajan, "Adulticidal properties of synthesized silver nanoparticles using leaf extracts of Feronia elephantum (Rutaceae) against filariasis, malaria, and dengue vector mosquitoes," Parasitology Research, vol. 113, no. 11, pp. 4085-4096, 2014.

[22] A. Kalaiselvi, S. M. Roopan, G. Madhumitha, C. Ramalingam, and G. Elango, "Synthesis and characterization of palladium nanoparticles using Catharanthus roseus leaf extract and its application in the photo-catalytic degradation," Spectrochimica Acta Part A: Molecular and Biomolecular Spectroscopy, vol. 135, pp. 116-119, 2015.

[23] A. El-Faham, A. A. Elzatahry, Z. A. Al-Othman, and E. A. Elsayed, "Facile method for the synthesis of silver nanoparticles using 3-hydrazino-isatin derivatives in aqueous methanol and their antibacterial activity," International Journal of Nanomedicine, vol. 9, no. 1, pp. 1167-1174, 2014.

[24] P. Rauwel, S. Küünal, S. Ferdov, and E. Rauwel, "A review on the green synthesis of silver nanoparticles and their morphologies studied via TEM," Advances in Materials Science and Engineering, vol. 2015, Article ID 682749, 9 pages, 2015.

[25] J. L. Gardea-Torresdey, E. Gomez, J. R. Peralta-Videa, J. G. Parsons, H. Troiani, and M. Jose-Yacaman, "Alfalfa sprouts: a natural source for the synthesis of silver nanoparticles," Langmuir, vol. 19, no. 4, pp. 1357-1361, 2003.

[26] S. S. Shankar, A. Ahmad, and M. Sastry, "Geranium leaf assisted biosynthesis of silver nanoparticles," Biotechnology Progress, vol. 19, no. 6, pp. 1627-1631, 2003.

[27] P. Phanjom, A. Sultana, H. Sarma, J. Ramchiary, K. Goswami, and P. Baishya, "Plant-mediated synthesis of silver nanoparticles using Elaeagnus latifolia leaf extract," Digest Journal of Nanomaterials and Biostructures, vol. 7, no. 3, pp. 1117-1123, 2012.

[28] S. Gurunathan, J. Raman, S. N. Abd Malek, P. A. John, and S. Vikineswary, "Green synthesis of silver nanoparticles using Ganoderma neo-japonicum Imazeki: a potential cytotoxic agent against breast cancer cells," International Journal of Nanomedicine, vol. 8, pp. 4399-4413, 2013.

[29] E. Viveros-Valdez, C. Rivas-Morales, P. Carranza-Rosales, S. Mendoza, and G. Schmeda-Hirschmann, "Free radical scavengers from the Mexican herbal tea poleo (Hedeoma drummondii)," Zeitschrift für Naturforschung C, vol. 63, no. 5-6, pp. 341-346, 2008.

[30] Paterson, "Phytochemical methods. A guide to modern techniques of plant analysis," Plant Pathology, vol. 48, no. 1, p. 146, 1999.

[31] S.-M. Tsaur, S.-C. Chang, K.-T. Luh, and W.-C. Hsieh, "Antimicrobial susceptibility of enterococci in vitro," Journal of the Formosan Medical Association, vol. 92, no. 6, pp. 547-552, 1993.

[32] T. Mosmann, "Rapid colorimetric assay for cellular growth and survival: application to proliferation and cytotoxicity assays," Journal of Immunological Methods, vol. 65, no. 1-2, pp. 55-63, 1983.

[33] L. B.-N. Lluvia Arteaga-Figueroa, M. Patiño-Vera, and V. L. Petricevich, "Antioxidant activity, total phenolic and flvonoid 
contents, and cytotoxicity evaluation of Bougainvillea xbuttiana," International Journal of Pharmacy and Pharmaceutcal Sciences, vol. 6, no. 5, pp. 1-6, 2014.

[34] M. Singh, I. Sinha, and R. K. Mandal, "Role of $\mathrm{pH}$ in the green synthesis of silver nanoparticles," Materials Letters, vol. 63, no. 3-4, pp. 425-427, 2009.

[35] K. D. Arunachalam, L. B. Arun, S. K. Annamalai, and A. M. Arunachalam, "Potential anticancer properties of bioactive compounds of Gymnema sylvestre and its biofunctionalized silver nanoparticles," International Journal of Nanomedicine, vol. 10, no. 1, pp. 31-41, 2014.

[36] A. B. Chanthini, G. Balasubramani, R. Ramkumar et al., "Structural characterization, antioxidant and in vitro cytotoxic properties of seagrass, Cymodocea serrulata (R.Br.) Asch. \& Magnus mediated silver nanoparticles," Journal of Photochemistry and Photobiology B: Biology, vol. 153, pp. 145-152, 2015.

[37] J. J. Antony, M. Nivedheetha, D. Siva et al., "Antimicrobial activity of Leucas aspera engineered silver nanoparticles against Aeromonas hydrophila in infected Catla catla," Colloids and Surfaces B: Biointerfaces, vol. 109, pp. 20-24, 2013.

[38] L. Shang, S. Dong, and G. U. Nienhaus, "Ultra-small fluorescent metal nanoclusters: synthesis and biological applications," Nano Today, vol. 6, no. 4, pp. 401-418, 2011.

[39] P. R. Van Tassel, "Nanotechnology in medicine: nanofilm biomaterials," Yale Journal of Biology and Medicine, vol. 86, no. 4, pp. 527-536, 2013.

[40] B. V. Bonifácio, P. B. da Silva, M. Aparecido dos Santos Ramos, K. Maria Silveira Negri, T. Maria Bauab, and M. Chorilli, "Nanotechnology-based drug delivery systems and herbal medicines: a review," International Journal of Nanomedicine, vol. 9, no. 1, pp. $1-15,2013$.

[41] I. Y. Wong, S. N. Bhatia, and M. Toner, "Nanotechnology: emerging tools for biology and medicine," Genes and Development, vol. 27, no. 22, pp. 2397-2408, 2013.

[42] J. D. Unciti-Broceta, T. Del Castillo, M. Soriano, S. Magez, and J. A. Garcia-Salcedo, "Novel therapy based on camelid nanobodies," Therapeutic Delivery, vol. 4, no. 10, pp. 1321-1336, 2013.

[43] D. M. Smith, J. K. Simon, and J. R. Baker Jr., "Applications of nanotechnology for immunology," Nature Reviews Immunology, vol. 13, no. 8, pp. 592-605, 2013.

[44] D. Nath and P. Banerjee, "Green nanotechnology—a new hope for medical biology," Environmental Toxicology and Pharmacology, vol. 36, no. 3, pp. 997-1014, 2013.

[45] A. M. Alwan, Z. Nesrullah, and E. Faraj, "Study the effect of ethanolic extract of Glycyrrhiza glabra on pathogenic bacteria," International Journal of Current Microbiology and Applied Sciences, vol. 4, no. 5, pp. 473-484, 2015.

[46] M. N. Asl and H. Hosseinzadeh, "Review of pharmacological effects of Glycyrrhiza sp. and its bioactive compounds," Phytotherapy Research, vol. 22, no. 6, pp. 709-724, 2008.

[47] S. Khadem and R. J. Marles, "Monocyclic phenolic acids; hydroxy- and polyhydroxybenzoic acids: occurrence and recent bioactivity studies," Molecules, vol. 15, no. 11, pp. 7985-8005, 2010.

[48] M. Ali, B. Kim, K. D. Belfield, D. Norman, M. Brennan, and G. S. Ali, "Green synthesis and characterization of silver nanoparticles using Artemisia absinthium aqueous extract-a comprehensive study," Materials Science and Engineering C, vol. 58, pp. 359-365, 2016.
[49] A. Navarrete, I. Oliva, M. E. Sánchez-Mendoza, J. Arrieta, L. Cruz-Antonio, and G. Castañeda-Hernández, "Gastroprotection and effect of the simultaneous administration of Cuachalalate (Amphipterygium adstringens) on the pharmacokinetics and anti-inflammatory activity of diclofenac in rats," Journal of Pharmacy and Pharmacology, vol. 57, no. 12, pp. 1629-1636, 2005.

[50] D. Nayak, S. Ashe, P. R. Rauta, M. Kumari, and B. Nayak, "Bark extract mediated green synthesis of silver nanoparticles: evaluation of antimicrobial activity and antiproliferative response against osteosarcoma," Materials Science and Engineering C, vol. 58, pp. 44-52, 2016.

[51] M. Safaepour, A. R. Shahverdi, H. R. Shahverdi, M. R. Khorramizadeh, and A. R. Gohari, "Green synthesis of small silver nanoparticles using geraniol and its cytotoxicity against fibrosarcoma-Wehi 164," Avicenna Journal of Medical Biotechnology, vol. 1, no. 2, pp. 111-115, 2009. 

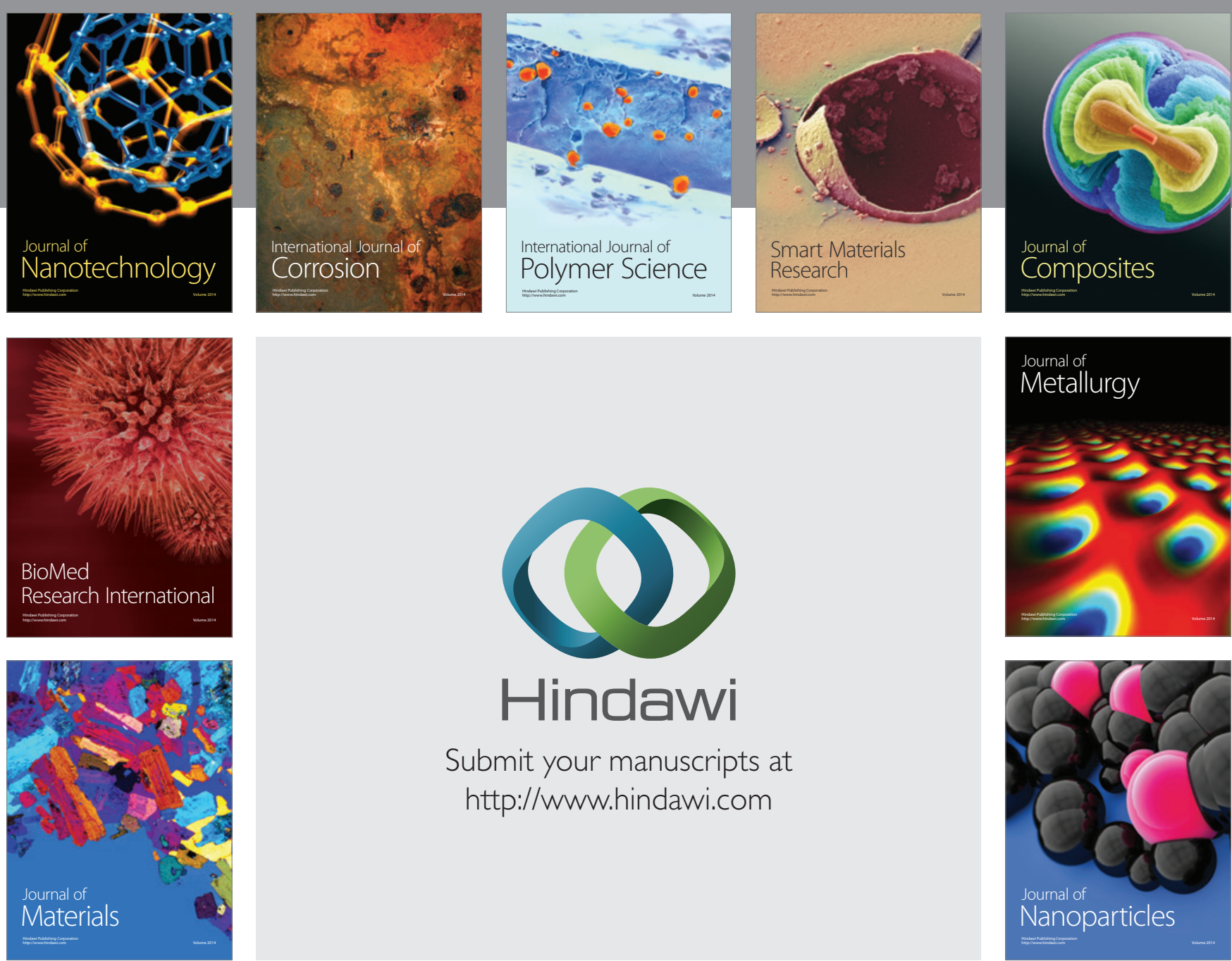

\section{Hindawi}

Submit your manuscripts at

http://www.hindawi.com

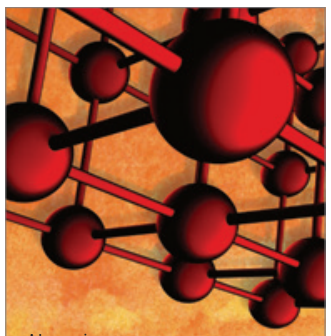

Materials Science and Engineering
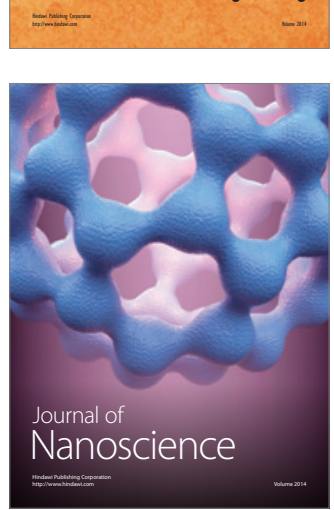
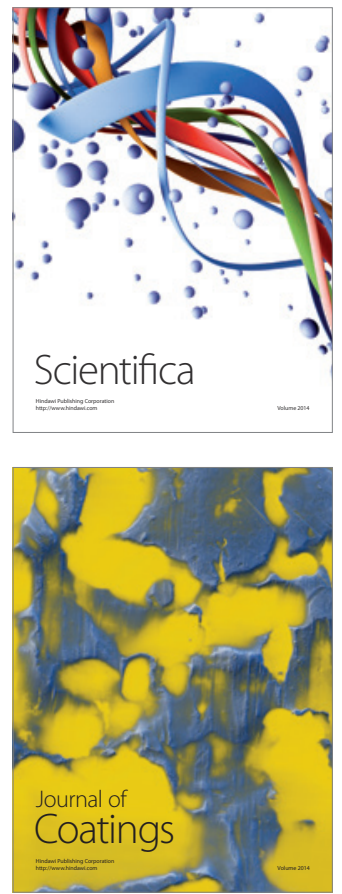
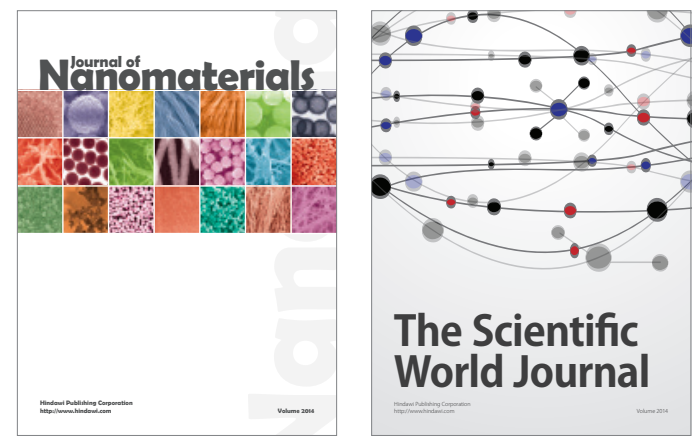

The Scientific World Journal
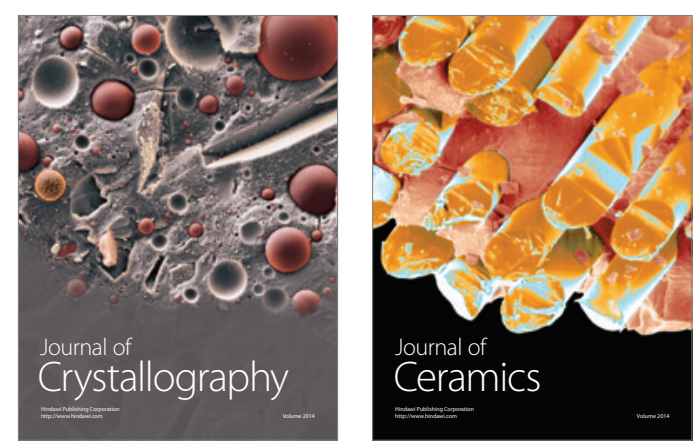
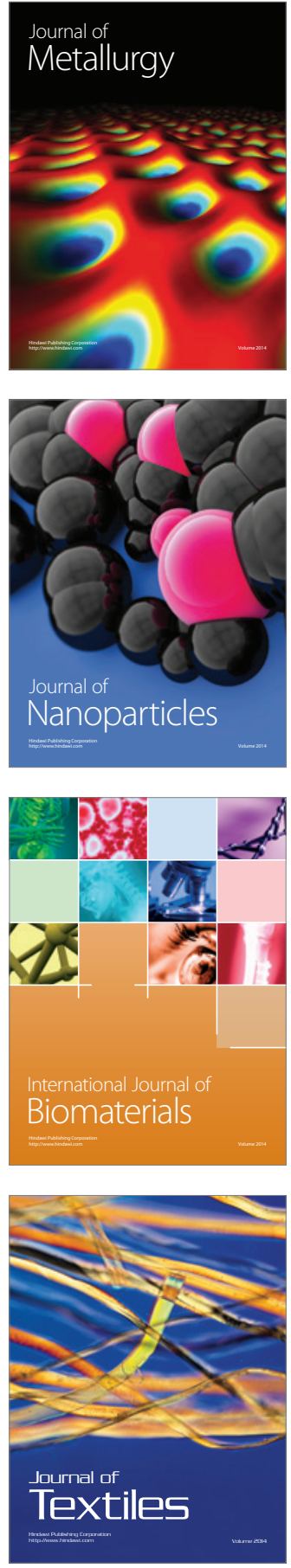